\title{
Transient response of passive matrix polymer LED displays
}

\author{
D. Braun ${ }^{\mathrm{a}}, \mathrm{K}$. Erickson ${ }^{\mathrm{a}}, \mathrm{G} . \mathrm{Yu}^{\mathrm{b}}$ \\ ${ }^{a}$ Electrical Engineering Department, Cal Poly State University, San Luis Obispo, California, U.S.A. \\ ${ }^{\mathrm{U}}$ UNIAX Corporation, Santa Barbara, California, U.S.A.
}

\begin{abstract}
Video displays based on polymer and organic displays require high resolution and high data rates. However, the transient response of passive matrix displays based on polymer and organic light-emitting diodes limits display resolution, image uniformity, and image contrast. We use circuit simulation in order to quantify these consequences. This work analyzes how the transient response depends on display resolution, display geometry, pixel position, and row and column electrode design. We conclude that advanced display designs can achieve uniform images at high resolution and contrast.
\end{abstract}

Keywords: Polymer light-emitting diode; Transient display response

\section{Introduction}

Much interest in polymer and organic light-emitting diodes derives from their potential to deliver the next generation of flat and flexible displays [1-9]. High information content and full motion video displays must display images with sufficient spatial resolution, speed and contrast to please the human eye. Previous work has explored techniques to improve display uniformity and resolution based on DC display characteristics [12]. This study explores how electrode resistance influences the transient display characteristics.

\section{Simulation Results}

Fig. 2 compares the transient response as pixel resolution increases along one row. The approach used is to insert the electrical data for a LED from Fig. 1 into the PSpice circuit simulation tool. The display contains pixels with the circuit shown in the inset to Fig. 1. Pixel area is $300 \mu \mathrm{m} \times 300 \mu \mathrm{m}=0.09 \mathrm{~mm}^{2}$ with $50 \mu \mathrm{m}$ spaces between pixels. Each pixel contains one LED, a row resistance of $R_{\text {Cathode }}=0.10 \mathrm{~m} \Omega$, a column resistance of $R_{\text {Anode }}=11.6 \Omega$, and a capacitance $C=40 \mathrm{pF}$. Given a metallic cathode with sufficiently low resistance, additional columns have little influence on the transient response. Column resistance limits performance.

Fig. 2 compares the transient response of one row to a $5 \mathrm{~V}$ pulse as pixel resolution increases. Given a metallic cathode with sufficiently low resistance, $0.1 \mathrm{~m} \Omega$ per pixel in this case, additional columns have little influence on the transient response. Column resistance limits speed [11].

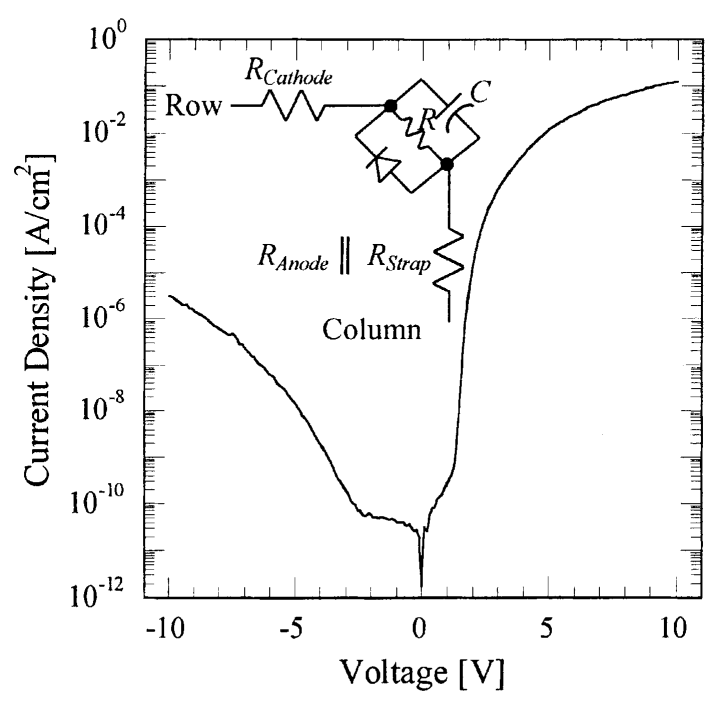

Fig. 1. Current as a function of voltage recorded for a polymer LED made from alkoxy-PPV. The inset shows the equivalent circuit of each pixel. 


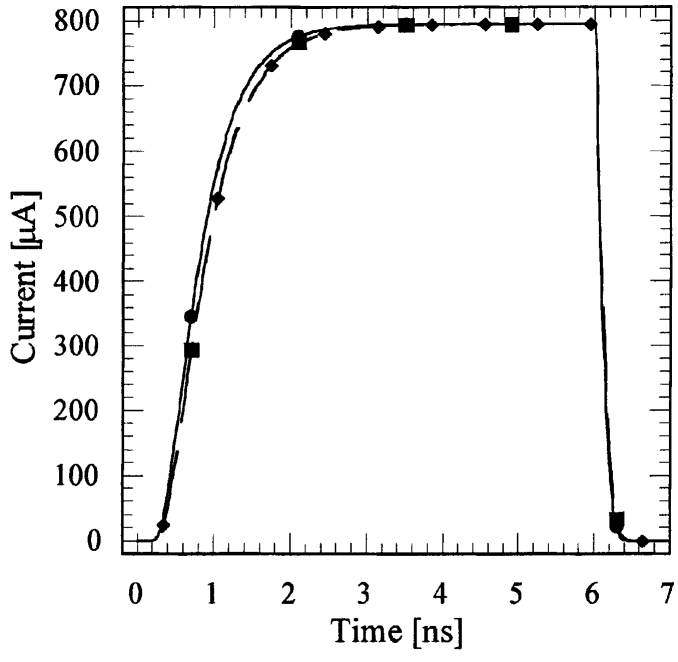

Fig. 2. Transient response along one row with one column (circles), 100 columns (squares), and 1000 columns (diamonds).

Fig. 3 compares the transient response along one column for various values of $R_{\text {Strap }}$, the resistance of an auxiliary electrode used to decrease anode resistance $[5,10]$. As column resistance limits performance, low $R_{\text {Strap }}$ is required to preserve display uniformity [12] and transient response. Fig. 4 confirms that low $R_{\text {Strap }}$ also improves the contrast of the display by allowing the display to discern more levels of brightness. The contrast calculation assumes a $100 \mathrm{~Hz}$ frame rate. The lowest gray level occurs if the pulse width equals the $90 \%$ point on the rising edge of the transient.

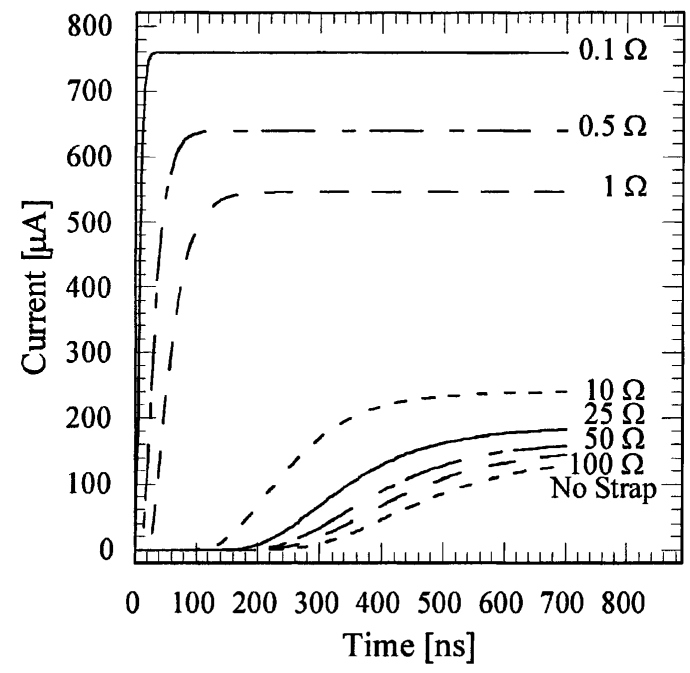

Fig. 3. Transient response along a column with 1000 rows for various values of $R_{\text {Strap }}$

\section{Conclusion}

Tradeoffs exist between display resolution and display contrast. This work has analyzed how the transient response of passive matrix polymer displays depends on display resolution and row and column electrode resistance.

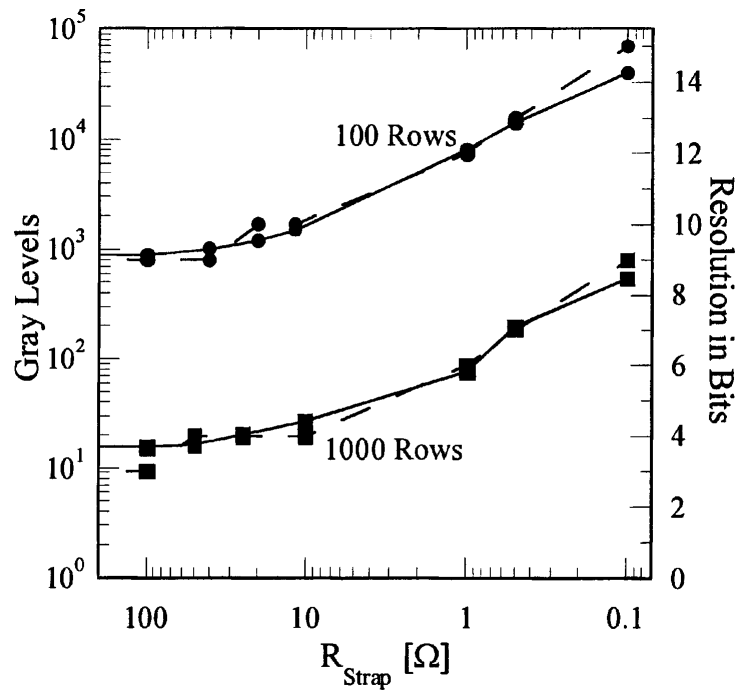

Fig. 4. Gray levels (solid lines) and bit resolution (dashed lines) vs. $R_{\text {Strap }}$.

Reducing anode electrode resistance with a parallel conduction path $\left(R_{\text {Strap }}\right)$ provides one key to transient response, assuming that the cathode electrode resistance is sufficiently low. Because anode-to-cathode capacitance influences display speed, thicker pixels can reduce pixel capacitance. Display response slows as row and column lengths increase, so lower resolution displays offer speedier response and greater contrast.

\section{References}

[1] C. W. Tang and S. A. VanSlyke, Appl. Phys. Lett. 51 (1987) 913.

[2] J. H. Burroughes, D. D. C. Bradley, A. R. Brown, R. N. Marks, K. Mackay, R. H. Friend, P. L. Burns, and A. B. Holmes, Nature 347 (1990) 539;

R. H. Friend, R. W. Gymer, A. B. Holmes, J. H. Burroughes, R. N. Marks, C. Taliani, D. D. C. Bradley, D. A. Dos Santos, J. L. Brédas, M. Lögdlund \& W. R. Salaneck, Nature 397 (1999) 121.

[3] D. Braun and A. J. Heeger, Appl. Phys. Lett. 58 (1991) 1982; G. Gustafsson, Y. Cao, G. M. Treacy, F. Klavetter, N. Colaneri, and A. J. Heeger, Nature 357 (1992) 477.

[4] Links contained in http://www.ee.calpoly.edu/ dbraun/polyelec/ moreinfo.html and http://www.chipcenter.com/eexpert/dbraun/ main.html, accessed June 27, 2000.

[5] M. T. Johnson and A. Sempel, Information Display 2/00 (2000) 12.

[6] R. F. Service, Science, 273 (1996) 878; J. R. Sheats, H. Antoniadis, M. Hueschen, W. Leonard, J. Miller, R. Moon, D. Roitman, and A. Stocking, Science 273 (1996) 884.

[7] Proceedings of the 1998 International Conference on Science and Technology of Synthetic Metals, Synth. Met., 102 (1999) 857; M.D. McGehee, E.K. Miller, D. Moses and A.J. Heeger, in P. Bernier, S. Lefrant and G. Bidan (eds.), Advances in Synthetic Metals: Twenty Years of Progress in Science and Technology, Elsevier, Amsterdam, 1999, p. 98

[8] G. Yu, K. Pakbaz, and A. J. Heeger, J. Electron. Mater. 23 (1994) 925

[9] P. W. M. Blom, M. J. M. de Jong, C. T. H. F. Liedenbaum, and J. J. M. Vleggaar, Synth. Met. 85 (1997) 1287.

[10]C. Hosokawa, M. Matsuura, M. Eida, K. Fukuoka, H. Tokailin, T. Kusumoto, http://www.sid.org/sid98/data/04_01.PDF, accessed June 27, 2000; T. Namiki, H. Satoh, K. Nagayama, T. Watanabe, Organic electroluminsecent device, US Patent No. 5399936 (1995).

[11] D. Braun, D. Moses, C. Zhang, and A. J. Heeger, Appl. Phys. Lett. 61 (1992) 3092.

[12]D. Braun, Synth. Met. 92 (1998) 107;

D. Braun, J. Rowe, G. Yu Synth. Met. 102 (1999) 120. 